\title{
THE EUKARYOTIC LINEAR MOTIF RESOURCE - ELM REGULATORY SITES IN PROTEINS
}

\section{What are Linear Motifs?}

Protein linear motifs (LMs) describe short, common stretches of polypeptide chains (typically peptides between $\mathbf{3}$ and $\mathbf{8}$ amino acid residues long) that embody a distinct molecular function independent of a larger sequence/structure context.

The LMs are nearly always involved in regulation. Their function is often mediated by interactions with one or more globular domain classes. Linear motifs bind to their interaction partners with low affinity, usually between 1.0 and 150 micromolar.

They often reside in disordered or low-complexity sequence regions within proteins, and often becoming ordered upon binding to another protein or domain.

Instances of linear motifs seem to arise or disappear as a result of point mutations. Unrelated proteins are likely to contain similar linear motif if sharing functional feature (i.e. convergent evolution of linea motifs)
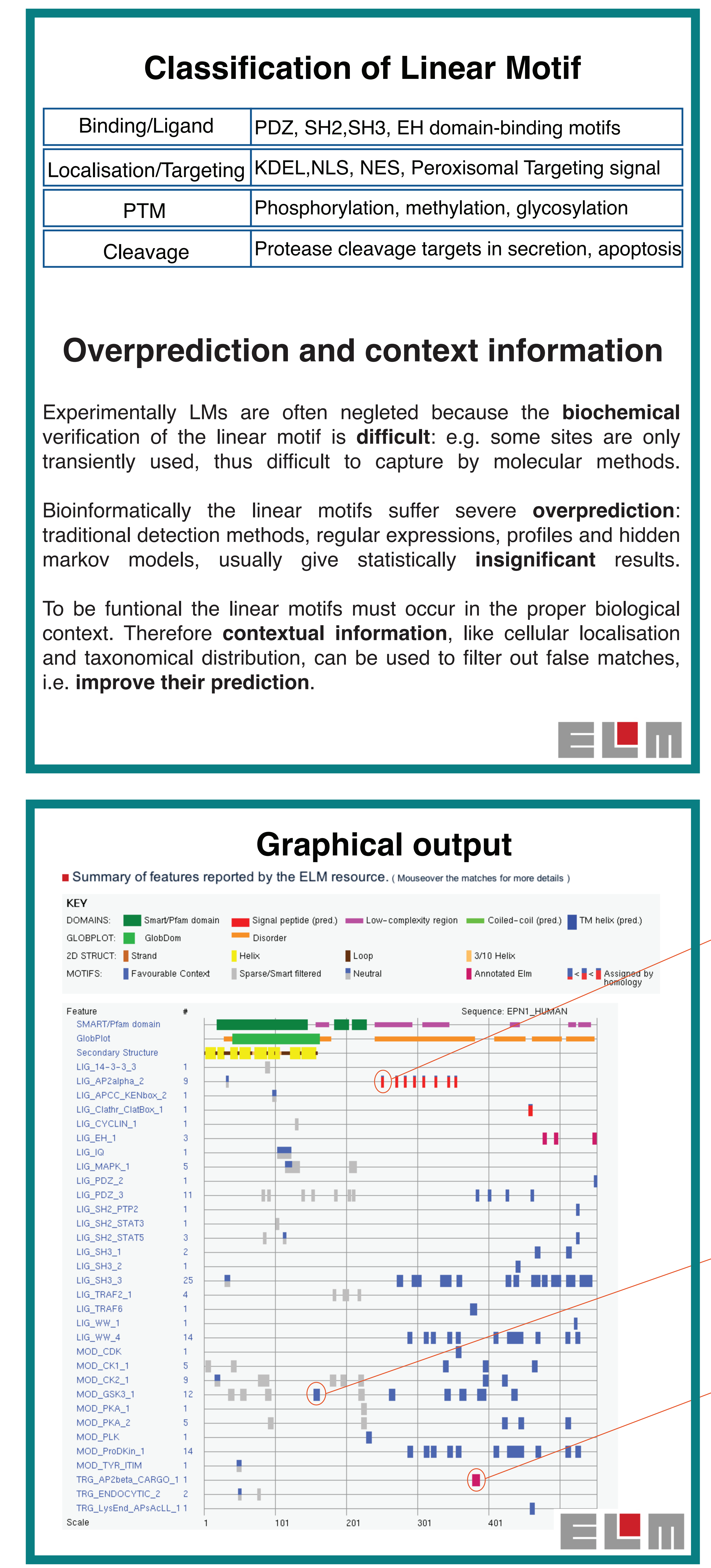

Linear Motifs in Endocytic and Recycling Pathway

Linear motifs play a key role in the regulation of many cellular processes. Clathrin-mediated 作 range of connections between proteins.

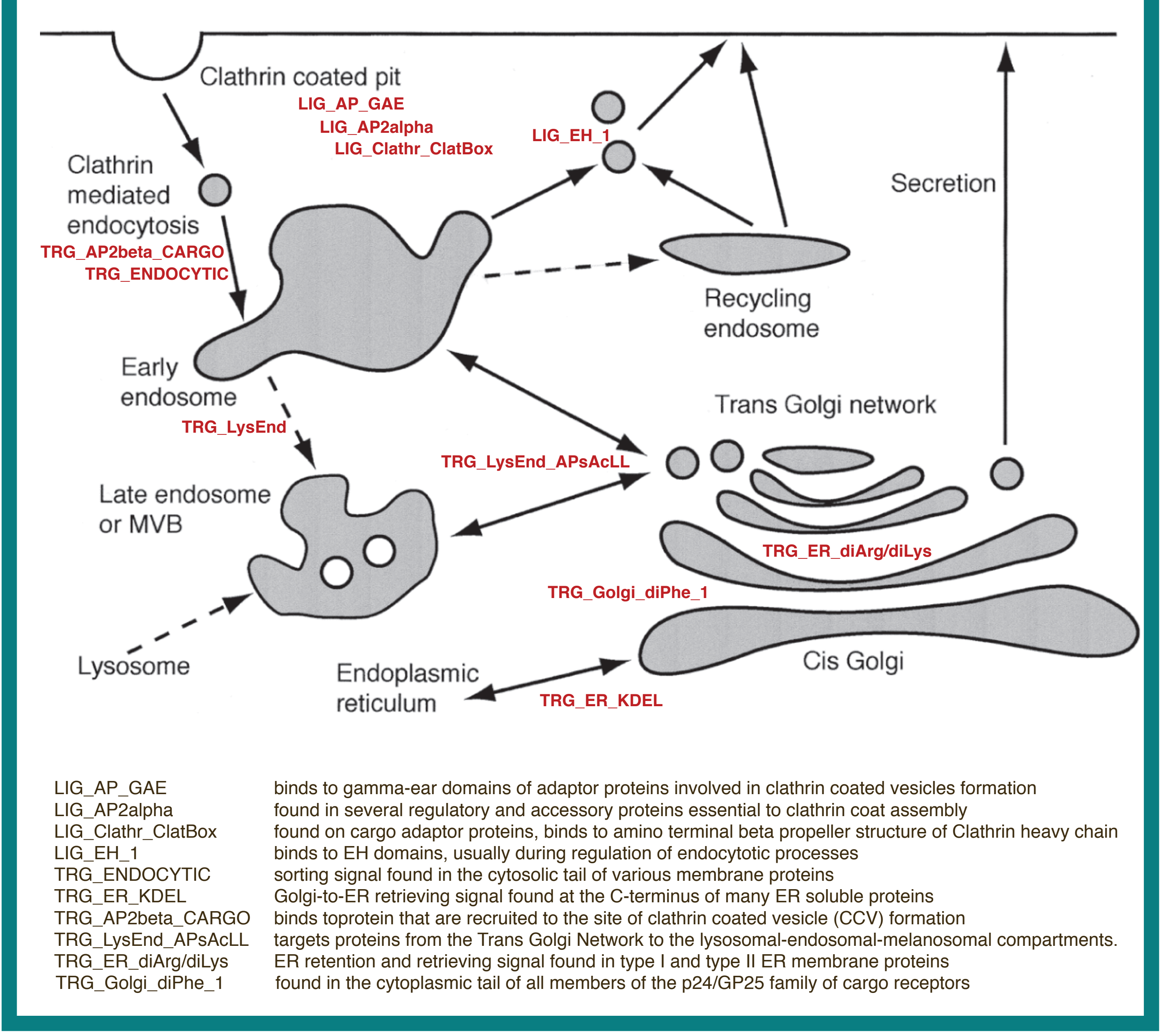

The Eukaryotic Linear Motif Resource ELM is both a knowledgebase and discovery tool:

- Repository of information about short linear motif, including experimentally reported instances

- Motif-based query tool to find possible new functional sites
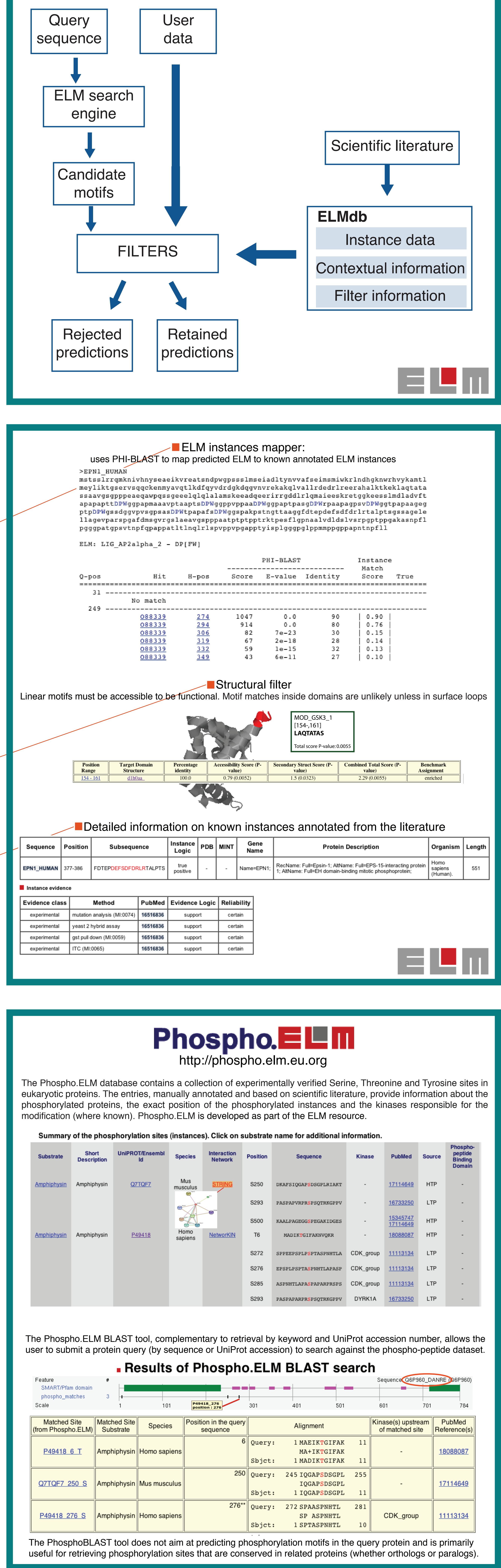